\title{
Comparative Cognition \& Behavior Reviews: the first six years
}

\author{
Robert Cook \\ Tufts University \\ Ron Weisman \\ Queen's University
}

\begin{abstract}
We reflect on beginning the electronic journal, Comparative Cognition \& Behavior Reviews (CCBR) and discuss its current status. We conclude that CCBR meets the continuing need for reviews of established bodies of knowledge about comparative cognition. It now attracts over ten thousand viewers per year and several thousand downloads of its full articles. Also, CCBR is steadily increasing in citations. We are pleased to hand over stewardship of CCBR to the new editors: Chris Sturdy and Tom Zentall.
\end{abstract}

Keywords: e-journals, web-based publishing, comparative cognition, impact.

Scientific societies have been the driving force behind the creation of scientific journals since the Royal Society invented the peer-review process in the 17th Century. Following in that splendid tradition, in 2005 the Comparative Cognition Society created Comparative Cognition \& Behavior Reviews (CCBR). Building on Bob Cook's experience in editing the eBook, Avian Visual Cognition, the Society appointed Bob Cook and Ron Weisman co-editors of the new journal for a six -year term.

In developing a model for CCBR, the Society sought to create a new peer-reviewed, open-access electronic journal of comprehensive reviews and short constructive critiques of research in animal cognition and behavior to be published annually on the Internet. The idea was to present the field of Comparative Cognition as a body of knowledge available to people everywhere. Of course, we were interested in reaching a broad range of scientists and in creating an attractive and useful resource in teaching advanced undergraduates and graduate students about our science, but we wanted to give it away to the world. This model received wide support

Robert Cook, Department of Psychology, 490 Boston Ave, Medford MA, 02155. Ronald Weisman, 99 University Avenue, Queen University, Kingston, Ontario, K7L 3N6, Canada. We thank the authors and reviewers whose excellent work made the first six years of CCBR possible. among Society members. The first volume of Comparative Cognition \& Behavior Reviews (CCBR) appeared in 2006.

From the beginning it was clear to the two of us that the key to the success of CCBR would be the creation of content that was of lasting and unique value to the scientific community. The quality of the journal is due to the originality and brilliance of the authors that we have edited and published over the years. We wish to extend our deepest thanks to the authors for everything that they have contributed to our field and toward helping to build the reputation of our journal.

We have sought a combination of invited and submitted reviews to be considered for publication. No paper, invited or submitted was guaranteed publication: peer review and active supervision from the editors were needed to ensure high quality articles. In our selection, we have consciously tried to include a broader array of topics than is typically associated with our field or covered in our textbooks. Thus, in the pages of the journal, readers will not only find material on traditional topics, such as associative learning or concept formation, but also computer intelligence and the origins of hominid thought and tool making. CCBR has also become the place to find lively exchanges of ideas around central themes in the study of comparative cognition.

Over the last six years, we have (largely) surmounted the 
numerous small and large technical and structural problems that beset any new electronic publishing venture. Creating and managing a web site and high quality downloadable content are an ongoing creative challenge. But dealing with the active bureaucracies who guard the gates by controlling the indexing of scientific journals has been and will continue to be a nightmare worthy of Franz Kafka. That said, we are pleased to report gains in CCBR's digital visibility. We are indexed by a growing number of science search engines, e.g., Google Scholar, Scopus, EBSCO, PsycINFO. An important objective for the future will be to obtain complete indexing by PubMed and the Web of Science.

Most recently, our indexing effects have begun to bear fruit in the most important impact metrics: the measures of our recognition by other scientists. We can measure this impact in several ways. We have been gathering statistics using a combination of Google Analytics and Google Scholar. Analytics tells us about our readers and Scholar tells us about our citations.

We only began tracking our journal's website using Analytics in the last year. For example, over 11,000 visitors from

Table 1.Top Ten Retrievals of 2010-2011. Every article published in CCBR in 2010 was retrieved at least 30 times.

\begin{tabular}{|c|c|c|}
\hline Rating & Retrievals & CCBR Reference \\
\hline 1 & 347 & $\begin{array}{l}\text { Tattersall, I. (2008). An Evolutionary Framework for the Acquisi- } \\
\text { tion of Symbolic Cognition by Homo sapiens. Comparative } \\
\text { Cognition \& Behavior Reviews, 3, 99-114. }\end{array}$ \\
\hline 2 & 97 & $\begin{array}{l}\text { Weisman, R. G. (2010). The Commentaries: Some are Visual } \\
\text { Illusions. Comparative Cognition \& Behavior Reviews, 5, 155- } \\
162 .\end{array}$ \\
\hline 3 & 94 & $\begin{array}{l}\text { Locurto, C. (2007). Individual differences and animal personality. } \\
\text { Comparative Cognition \& Behavior Reviews, 2, 67-78. }\end{array}$ \\
\hline 4 & 93 & $\begin{array}{l}\text { Fagot, J., \& Parron, C. (2010). Picture perception in birds: Perspec- } \\
\text { tive from primatologists. Comparative Cognition \& Behavior } \\
\text { Reviews, 5, 132-135 }\end{array}$ \\
\hline 5 & 83 & $\begin{array}{l}\text { Balsam, P. D., Drew, M. R., Gallistel, C. R. (2010). Time and Associa- } \\
\text { tive Learning. Comparative Cognition \& Behavior Reviews, } 5 \\
\text { 1-22. }\end{array}$ \\
\hline 6 & 74 & $\begin{array}{l}\text { Weisman, R. G., Spetch, M. L. (2010). Determining When Birds } \\
\text { Perceive Correspondence Between Pictures and Objects: A } \\
\text { Critique. Comparative Cognition \& Behavior Reviews, 5, 117- } \\
\text { 131. }\end{array}$ \\
\hline 7 & 54 & $\begin{array}{l}\text { Soto, F. A., \& Wasserman, E. A. (2010). Comparative vision science: } \\
\text { Seeing eye to eye? Comparative Cognition \& Behavior } \\
\text { Reviews, 5, 148-154. }\end{array}$ \\
\hline 8 & 53 & $\begin{array}{l}\text { Spetch, M.L. (2010). Understanding how pictures are seen is } \\
\text { important for comparative visual cognition. Comparative } \\
\text { Cognition \& Behavior Reviews, 5, 163-166. }\end{array}$ \\
\hline 9 & 46 & $\begin{array}{l}\text { Lea, S.E. G. (2010). What's the use of picture discrimination } \\
\text { experiments? Comparative Cognition \& Behavior Reviews, } 5 \text {, } \\
\text { 143-147. }\end{array}$ \\
\hline 10 & 45 & $\begin{array}{l}\text { Galef, B. G. Jr. (2008). Social Influences on the Mate Choices of } \\
\text { Male and Female Japanese Quail. Comparative Cognition \& } \\
\text { Behavior Reviews, 3, 1-12 }\end{array}$ \\
\hline
\end{tabular}

123 countries viewed the 2010 volume of CCBR. The top ten web retrievals of articles over the period August 1, 2010 to April 1, 2011 are listed in Table 1. Thetop four retrievals account for the bulk of the retrievals, but the other eight publications have gathered respectable readerships, too. The articles in CCBR 2010 have all been retrieved by at least 30 readers and over 200 readers have retrieved some articles. These statistics suggest that CCBR is increasingly well read. Scientific journals do not usually measure their readership, but surely science is not just about impact on other publications, it is also about the orderly dispersal of sound knowledge.

Google Analytics also tells us that the most common route to CCBR is via Google Scholar. This is no surprise since it is the most frequently used scientific search engine on the planet (and part of Google's master plan to be the first world government).

In addition to tracking readership, we have begun to track the number of citations to the entire collection of articles that constitutes CCBR. This is an important and easily computed measure of scientific impact. In Figure 1, we show the number of citations to CCBR over the last five years, as collected by Google Scholar. Not surprisingly, it has taken

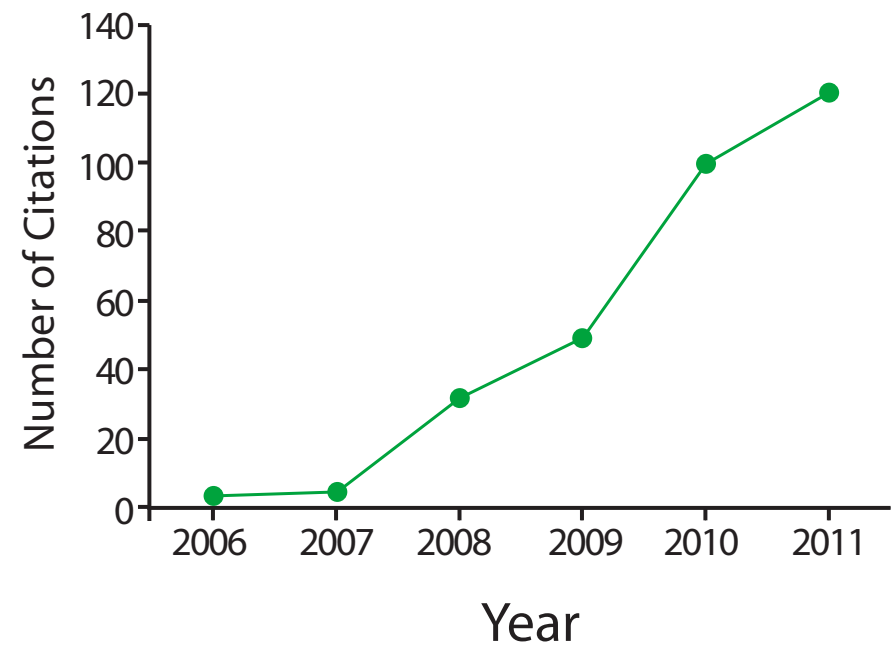

Figure 1. The number of citations over the years of CCBR publication from 2006 to 2011 (compiled from Google Scholar).

several years for our impact to be established, but the consistent upward trend is promising and strongly suggests that we are providing content that other scientist view as important. While not included here, we have tracked citation rates for several other journals in animal cognition. These kinds of comparisons indicate that we are doing well within our field. The top five currently most cited articles are listed in Table 2. 
Table 2. Top Five Cited CCBR Articles

\begin{tabular}{|c|c|c|}
\hline Title & Year & Citations \\
\hline $\begin{array}{l}\text { Comparative Social Cognition: } \\
\text { From wolf and dog to humans }\end{array}$ & 2007 & 20 \\
\hline
\end{tabular}

$\begin{array}{lll}\begin{array}{l}\text { Issues in the Comparative } \\ \text { Cognition of Abstract-Concept } \\ \text { Learning }\end{array} & 2007 & 18 \\ \begin{array}{l}\text { Tool-Related Cognition in } \\ \text { New Caledonian Crows }\end{array} & 2007 & 17\end{array}$

\begin{tabular}{lll} 
Concept Learning in Animals & 2008 & 13 \\
\hline Metacognition in Animals & 2009 & 9
\end{tabular}

Multiple demonstrations of
metacognition in nonhumans:
Converging evidence or multiple
mechanisms?

From the start, we planned that editorship of CCBR should change regularly to provide a continuing fresh prospective on our science. The new editors, Tom Zentall and Chris Sturdy, have already begun to review submitted manuscripts and invite potential articles. We are confident that the new editors are stepping onto a solid foundation. Construction will continue, but we are building a useful journal. CCBR is becoming the source for authoritative reviews on all aspects of comparative cognition and behavior..

In summary, we are pleased to report CCBR's progress over its inaugural volumes. First, it continues to exist. Second, it annually publishes high quality peer-reviewed content on a wide variety of topics. Third, its digital visibility and scientific impact are increasing. Finally, thanks to the generosity of members of the Society, it remains open access: open to readers around the world.

\section{Coda: Open access and peer review.}

From the onset, as the editors, we have strongly believed that the future of scientific publishing would be deeply intertwined with the Internet. Because of this, we have sought to provide a prominent place for the scientific study of cognition in animals on the web. This reasoning has been strongly confirmed. With the almost daily demise of another print newspaper and the remarkable growth of digital readers in the last years, as a salient example, it has become clear that a prominent place at the digital table is mandatory for any journal. The tangible benefits of electronic publication were obvious: much lower costs, rapid distribution, and higher quality. From the beginning, high-quality color reproduction of illustrations and figures became the standard in CCBR. Print journals offer some of these features, but only at exorbitant cost and then only to a very limited audience.

Cost is an important consideration because of our commitment to make the journal assessable to everyone without financial, legal, or technical barriers. It seemed to us, and a large number of others, that privatizing scientific information as a means of making money for commercial publishers is anathema to the goals of all scientists and to the pursuit of scientific progress. Thus, since the beginning the CCS has been subsidizing the publication of the journal in order to pursue this important objective. While some journals pursue fee-based models that require authors or institutions to cover the costs of publishing, we want to be clear that our journal is driven exclusively by the only critical feature of published science: peer-reviewed quality. 